Gut, 1978, 19, 1057-1058

\title{
Venous prostaglandin-like activity in diarrhoeal states
}

\author{
D. W. HARRIS, C. H. J. SWAN, AND P. R. SMITH \\ From the Department of Gastroenterology, North Staffordshire Hospital Centre, Stoke-on-Trent
}

SUMmaRY Prostaglandin $\mathrm{E}_{2}$-like activity was determined in peripheral venous blood of control subjects and in patients with acute gastroenteritis and active ulcerative colitis, using a bioassay method. No significant diurnal variations of prostaglandin levels were detected in the control group, while significantly raised venous plasma prostaglandin-like activity was detected in acute gastroenteritis and in active ulcerative colitis.

Administered prostaglandin (PGs) can produce diarrhoea (Misiewicz et al., 1969; Karim and Filshie, 1970; Karim, 1971) and PGs have been implicated in certain pathological conditions where diarrhoea is present (Sandler et al., 1968; Williams et al., 1968). PGs are also believed to be involved in inflammation (Willis, 1969; Giroud and Willoughby, 1970; Greaves et al., 1971) and the production of pain (Ferreira, 1972). The present investigations were to examine PG release in intestinal inflammatory disorders where diarrhoea or disturbed motility are prominent symptoms.

\section{Methods}

Peripheral venous blood $(10 \mathrm{ml})$ was removed from patients undergoing outpatient assessment of active ulcerative colitis, from patients with acute gastroenteritis, and from bed-rested patients in an orthopaedic ward who showed no signs of gastrointestinal or inflammatory disease (control group). None of the control subjects was undergoing treatment with non-steroidal anti-inflammatory drugs. Blood was withdrawn by disposable plastic syringe, transferred to chilled lithium heparin tubes, and centrifuged immediately. PGs were extracted from plasma using Amberlite XAD-2 resin in columns $10 \mathrm{~cm} \times 0.7 \mathrm{~cm}$ diameter as described by Keirse and Turnbull (1973). Experiments performed after the addition of known amounts of tritiated PGs to blood samples gave recoveries from the columns consistently in the range $79-83 \%$. PG-like activity was assayed using a rat stomach fundic strip (Vane, 1957) using pure $\mathrm{PGE}_{2}$ as standard (UpJohn Company Ltd). The preparation was perfused with $\mathrm{Krebs}$ solution $\left(37^{\circ} \mathrm{C}\right)$ made more specific for PGs by the addition of antagonists (hyoscine, methysergide, mepyramine

Received for publication 19 June 1978 all at $0 \cdot 2 \mu \mathrm{g} / \mathrm{ml}$ : pronethanol and indomethacin at $1 \mu \mathrm{g} / \mathrm{ml}$ ) and gassed with $95 \% \mathrm{O}_{2}+5 \% \mathrm{CO}_{2}$. Presence of specific PGs was confirmed by thin layer chromatography (Green and Samuelsson, 1964). Results were analysed statistically using Student's $t$ test.

\section{Results}

VENOUS PROSTAGLANDIN LEVELS IN CONTROL GROUP

The plasma $\mathrm{PGE}_{2}$-like activity in peripheral venous blood taken from 42 control subjects at three times during the day is shown in Table 1 . These subjects

Table 1 Venous plasma levels of prostaglandin-like activity at $08.30,12.00$, and 16.30 hours

\begin{tabular}{|c|c|c|c|}
\hline & \multicolumn{3}{|l|}{ Time } \\
\hline & 08.30 & 12.00 & 16.30 \\
\hline \multirow{3}{*}{$\begin{array}{l}\text { Males } \\
\text { Femal es } \\
\text { Males and } \\
\quad \text { females }\end{array}$} & $0.81 \pm 0.20(23)$ & $0.55 \pm 0.17(22)$ & $0.45 \pm 0.26(20)$ \\
\hline & $0.74 \pm 0.18$ (19) & $0.52 \pm 0.13(19)$ & $1.1 \pm 0.28$ (16) \\
\hline & $0.78 \pm 0.13(42)$ & $0.53 \pm 0.11(41)$ & $0.73 \pm 0.20(36)$ \\
\hline
\end{tabular}

Figures are $\mathrm{ng} \mathrm{PGE}_{\mathrm{q}}$-equivalents/ml plasma $\pm 1 \mathrm{SEM}$. The numbers of measurements are given in parentheses.

were bed-rested patients recovering from minor orthopaedic surgery and had no detected inflammatory or gastrointestinal diseases. The differences in $\mathrm{PGE}_{2}$-like activity seen throughout the day in each of the three groups (male, female, and combined) were not statistically significant $(P>0 \cdot 1)$. The differences in activity between groups, at corresponding collection times, were not statistically significant $(\mathbf{P}>\mathbf{0} \cdot 1)$. The control venous plasma concentration was $0.68 \pm 0.08$ (SEM) $\mathrm{ng} ; \mathrm{PGE}_{2}$ equivalents $/ \mathrm{ml}(\mathrm{n}=119)$. 
PLASMA PROSTAGLANDIN E2-LIKE ACTIVITY IN ACUTE GASTROENTERITIS AND ULCERATIVE COLITIS

The plasma $\mathrm{PGE}_{2}$-like activity in peripheral venous blood from nine patients admitted to hospital with acute gastroenteritis was $5 \cdot 3 \pm 1 \cdot 3$ (SEM) ng; $\mathrm{PGE}_{2}$ equivalents/ml (Table 2). This was signifi-

Table $2 P G E_{2}$-like activity in peripheral venous plasma

\begin{tabular}{lcl}
\hline Subjects & Number & $\begin{array}{l}P G E_{\text {y-like activity* }} \\
(\text { ng/ml plasma })\end{array}$ \\
\hline Control & 119 & $0.68 \pm 0.08$ \\
Acute gastroenteritis & 9 & $5 \cdot 3 \pm 1 \cdot 3$ \\
Active ulcerative colitis & 6 & $6 \cdot 5 \pm 1 \cdot 2$ \\
\hline
\end{tabular}

* Figures are mean \pm 1 SEM.

cantly greater than the control value $(P<0.01)$. Plasma PGE $_{2}$-like activity in six patients with active ulcerative colitis was $6.5 \pm 1 \cdot 2$ (SEM) ng/ml, significantly greater than the control value $(\mathrm{P}<0.01)$.

\section{Discussion}

The occurrence of high levels of PGE-like activity in the peripheral venous circulation is surprising, as PGs are thought to be rapidly removed by passage through the lungs (Piper et al., 1970). The results may indicate survival of PGs in the lungs, or, more likely, the activity (in the bioassay system) of PG metabolites. An endogenous inhibitor of PG synthetase (EIPS) in human plasma has recently been described (Saeed et al., 1977). These workers suggest the possibility that EIPS may control PG synthesis. In patients with acute ulcerative colitis deficiency of such a mechanism could lead to increased PG synthesis.

The control venous plasma PG-like material value is rather high and may represent $P G$ formation during handling, as no PG synthetase inhibitor was added to blood samples after collection. Nevertheless, a statistically significant difference exists between values obtained from patients and controls.

There is indirect evidence that the diarrhoeagenic action of cholera exotoxin may involve PG production; pretreatment of animals with non-steroidal anti-inflammatory agents which inhibit PG synthetase reduces intestinal fluid secretion (Finck and Katz, 1972; Jacoby and Marshall, 1972). The diarrhoea associated with gastroenteritis and ulcerative colitis probably results from large amounts of
PGs produced within the inflamed intestinal mucosa. We present here evidence for increased levels of PGE-like material in extracts of peripheral venous blood from patients with acute infective gastroenteritis and active ulcerative colitis. It is proposed that PGs play a role in the pathophysiology of inflammatory bowel diseases and may be responsible for production of diarrhoea in these conditions. It is still unclear whether increased PG production is a primary cause or a result of inflammation.

\section{References}

Ferreira, S. H. (1972). Prostaglandins, aspirin-like drugs and analgesia. Nature (New Biology), 240, 20C-203.

Finck, A. D., and Katz, R. L. (1972). Prevention of cholerainduced intestinal secretion in the cat by aspirin. Nature, 238, 273-274.

Giroud, J. P., and Willoughby, D. A. (1970). The interrelations of complement and a prostaglandin-like substance in acute inflammation. Journal of Pathology, 101, 241-249.

Greaves, M. W., Søndergaard, J., and McDonald-Gibson, W. (1971). Recovery of prostaglandins in human cutaneous inflammation. British Medical Journal, 2, 258-260.

Green, K., and Samuelsson, B. (1964). Prostaglandins and related factors. XIX. Thin-layer chromatography of prostaglandins. Journal of Lipid Research, 5, 117-120.

Jacoby, H. I., and Marshall, C. H. (1972). Antagonism of cholera enterotoxin by anti-inflammatory agents in the rat. Nature, 235, 163-165.

Karim, S. M. M. (1971). Effects of oral administration of prostaglandins $E_{2}$ and $F_{2}$ alpha on the human uterus. Journal of Obstetrics and Gynaecology of the British Commonwealth, 78, 289-293.

Karim, S. M. M., and Filshie, G. M. (1970). Therapeutic abortion using prostaglandin $F_{2}$ alpha. Lancet, 1, 157-159.

Keirse, M. J. N. C., and Turnbull, A. C. (1973). Extraction of prostaglandins from human blood. Prostaglandins, 4, 607 617.

Misiewicz, J. J., Waller, S. L., Kiley, N., and Horton, E. W. (1969). Effect of oral prostaglandin $E_{1}$ on intestinal transit in man. Lancet, 1, 648-651.

Piper, P. J., Vane, J. R., and Wyllie, J. H. (1970). Inactivation of prostaglandins by the lungs. Nature, 225, 600-604.

Saeed, S. A., McDonald-Gibson, W. J., Cuthbert, J., Copas, J. L., Schneider, C., Gardiner, P. J., Butt, N. M., and Collier, H. O. J. (1977). Endogenous inhibitor of prostaglandin synthetase. Nature, 270, 32-36.

Sandler, M., Karim, S. M. M., and Williams, E. D. (1968) Prostaglandins in amine-peptide-secreting tumours. Lancet, 2, 1053-1055.

Vane, J. R. (1957). A sensitive method for the assay of 5-hydroxytryptamine. British Journal of Pharmacology, 12, 344.

Williams, E. D., Karim, S. M. M., and Sandler, M. (1968). Prostaglandin secretion by medullary carcinoma of the thyroid. Lancet, 1, 22-23.

Willis, A. L. (1969). Release of histamine, kinin and prostaglandins during carrageenin-induced inflammation in the rat. In Prostaglandins, Peptides and Amines, pp. 31-38. Edited by P. Mantegazza and E. W. Horton. Academic Press: London. 